\title{
Article \\ The Contribution of Registered Dietitians in the Management of Hyperemesis Gravidarum in the United Kingdom
}

\author{
Kate Maslin ${ }^{1, *(\mathbb{D}, \text {, Hazel A. Billson }}{ }^{2}$, Caitlin R. Dean ${ }^{3} \mathbb{D}$ and Julie Abayomi ${ }^{4} \mathbb{D}$ \\ 1 School of Nursing and Midwifery, Faculty of Health, University of Plymouth, Plymouth PL4 8AA, UK \\ 2 Department of Nutrition \& Dietetics, Liverpool Women's NHS Foundation Trust, Liverpool L8 7SS, UK; \\ hazel.billson@lwh.nhs.uk \\ 3 Obstetrics and Gynecology, Medical Centre, University of Amsterdam, \\ 1105 AZ Amsterdam, The Netherlands; caitlinrdean@gmail.com \\ 4 Applied Health and Social Care, Edge Hill University, Ormskirk L39 4QP, UK; abayomij@edgehill.ac.uk \\ * Correspondence: kate.maslin@plymouth.ac.uk
}

Citation: Maslin, K.; Billson, H.A.; Dean, C.R.; Abayomi, J. The Contribution of Registered Dietitians in the Management of Hyperemesis Gravidarum in the United Kingdom. Nutrients 2021, 13, 1964. https:// doi.org/10.3390/nu13061964

Academic Editor: M. Victoria Arija Val

Received: 17 May 2021

Accepted: 3 June 2021

Published: 8 June 2021

Publisher's Note: MDPI stays neutral with regard to jurisdictional claims in published maps and institutional affiliations.

Copyright: () 2021 by the authors. Licensee MDPI, Basel, Switzerland. This article is an open access article distributed under the terms and conditions of the Creative Commons Attribution (CC BY) license (https:// creativecommons.org/licenses/by/ $4.0 /)$.

\begin{abstract}
Hyperemesis Gravidarum (HG) is a condition at the extreme end of the pregnancy sickness spectrum, which can cause poor oral intake, malnutrition, dehydration and weight loss. The aim of this study is to explore the role of Registered Dietitians (RD) in the management of HG in the United Kingdom (UK). A survey was designed and distributed electronically to members of the British Dietetic Association. There were 45 respondents, $76 \%(n=34)$ worked in secondary care hospitals, $11 \%(n=5)$ were in maternal health specialist roles. The most commonly used referral criteria was the Malnutrition Universal Screening Tool $(40 \%, \mathrm{n}=18)$, followed by second admission $(36 \%, n=16)$. However $36 \%(n=16)$ reported no specific referral criteria. About $87 \%(n=37)$ of respondents did not have specific clinical guidelines to follow. Oral nutrition supplements were used by $73 \%(n=33)$ either 'sometimes' or 'most of the time'. Enteral and parenteral nutrition were less commonly used. There was an inconsistent use of referral criteria to dietetic services and a lack of specific clinical guidelines and patient resources. Further training for all clinicians and earlier recognition of malnutrition, alongside investment in the role of dietitians were recommended to improve the nutritional care of those with HG.
\end{abstract}

Keywords: pregnancy sickness; pregnancy nutrition; gestational malnutrition; hyperemesis gravidarum; maternal nutrition

\section{Introduction}

Nausea and vomiting are reported to be experienced by around $70 \%$ of pregnant women [1]. Hyperemesis Gravidarum (HG) is a more severe condition at the extreme end of the pregnancy sickness spectrum. It is estimated to affect $1.5 \%$ of pregnant women in the United Kingdom (UK) [2], with rates of $0.8-3.3 \%$ reported in other populations [3-6]. There is no agreed definition of HG, which makes diagnosis, management and research challenging; but HG is typically reported as involving persistent and intractable nausea and vomiting with the triad of more than $5 \%$ pre-pregnancy weight loss, dehydration and electrolyte imbalance [7]. The historical belief that HG is self-limiting without any short or long-term consequences has been largely disproven [8]. Symptoms of HG can be persistent, resulting in prolonged poor oral intake, malnutrition, dehydration and weight loss [9-11]. Consequently, HG can increase the risk of negative outcomes for the offspring, including preterm birth or being small for gestational age, with growing evidence of the risk for long-term effects also [12,13]. In severe cases, HG can result in Wernicke's encephalopathy or even maternal death [14]. The exact aetiology of $\mathrm{HG}$ is poorly understood, although a genetic origin, associated with cachexia, has been identified [15].

In the absence of a definitive cause, the management of HG focuses on symptom relief and the prevention of serious morbidity [16]. First line advice recommends that women 
who are vomiting, but are not dehydrated, can be managed in the community with oral antiemetic medication, support, reassurance, oral hydration and dietary advice $[7,9]$. In practice, hospital treatment with intravenous (IV) fluids, IV antiemetic medication and vitamin B1 supplements is often required. As there is little high quality and consistent evidence supporting any one intervention, effective treatment often requires a combination of medical interventions, dietary and lifestyle changes, supportive care and patient education [9]. Although poor nutritional intake is often a key feature and consequence of HG, there is a lack of research about dietary intake and/or nutritional interventions [17-19]. A recent consultation [20], combining views from patients, clinicians and researchers prioritised the ten most important unanswered questions about HG, three of which directly relate to nutritional effects and management.

Those affected by HG can experience micronutrient deficiencies, severe food aversions and poor nutritional intake, in addition to gastroesophageal reflux and gastroparesis [11]. A dietetic consultation may be helpful in assessing and monitoring nutritional status, expanding food choices, and prescribing oral nutritional support where indicated [9]. In some severe cases, more intensive nutritional management using enteral nutrition (EN) may be appropriate. It is recommended that a dietitian should be consulted when tube feeding is being considered [7], although the evidence base is mixed and international practices vary $[18,21]$. Due to poor intake, unintentional weight loss and electrolyte imbalance, HG may increase the risk of refeeding syndrome. Dietetic advice can be very helpful in advising on its prevention and treatment [9]. Apart from this, the nature and extent of dietetic involvement in the management of HG is not known. The aim of this study is to explore the role of dietetic practice in the management of pregnancies affected by HG in the UK, with a focus on referral criteria, clinical management and strategies to improve nutritional outcomes.

\section{Materials and Methods}

\subsection{Participants and Recruitment}

Participants were Registered Dietitians practising in the UK who had ever had a patient referred to them with suspected or confirmed HG. A link to the information sheet and electronic questionnaire (see supplementary file S1) was distributed to members of the British Dietetic Association (BDA). Data collection took place for six weeks during November-December 2020 using the 'Online Surveys' platform. As this was an exploratory study, a sample size calculation was not required.

\subsection{Survey Design and Piloting}

A short questionnaire was developed based on the study objectives following a comprehensive literature review. It was piloted amongst a small group of dietitians and a patient advocate and then adjusted accordingly. Changes included asking more details about the use of enteral and parenteral nutrition.

\subsection{Data Analysis and Storage}

Data were exported from Online Surveys to Statistical Package for the Social Sciences version 24.0 [22]. Normality of data was assessed, showing data were non-normally distributed. Quantitative data were analysed using descriptive statistics and frequencies. Correlations were undertaken using a one-sided Spearman's rho. Statistical significance was assumed at $p<0.05$. Responses to open ended question were assessed and categorised into themes using Braun and Clarke's step by step guide [23].

\section{Results}

\subsection{Participant Characteristics, Clinical Setting and Role}

Total of 45 participants completed the survey, of which the majority worked in a secondary care hospitals in England. Only $5(11 \%)$ respondents had a principal role as a maternal health dietitian. Further details are shown in Table 1. 
Table 1. Respondent characteristics.

\begin{tabular}{|c|c|c|}
\hline & Response Options & $\%(n)$ \\
\hline \multirow{5}{*}{ Clinical setting } & Secondary care NHS hospital & $76(34)$ \\
\hline & Tertiary care NHS hospital & $11(5)$ \\
\hline & Specialist NHS maternity hospital & $4(2)$ \\
\hline & Private hospital & $0(0)$ \\
\hline & Other & $9(4)$ \\
\hline \multirow{4}{*}{ Country } & England & $64(29)$ \\
\hline & Scotland & $11(5)$ \\
\hline & Wales & $9(4)$ \\
\hline & Northern Ireland & $16(7)$ \\
\hline \multirow{4}{*}{ Work experience as a dietitian } & $<2$ years & $16(7)$ \\
\hline & $2-5$ years & $24(11)$ \\
\hline & $6-10$ years & $9(4)$ \\
\hline & $>10$ years & $51(23)$ \\
\hline \multirow{5}{*}{ Main role/specialism } & General/newly qualified & $20(9)$ \\
\hline & Gastroenterology & $16(7)$ \\
\hline & Nutrition Support Team & $20(9)$ \\
\hline & Maternal health dietitian & $11(5)$ \\
\hline & Other $^{1}$ & $36(16)$ \\
\hline \multirow{3}{*}{$\begin{array}{c}\text { Service level agreement to provide } \\
\text { dietetic cover to maternity/obstetrics } \\
\text { patients }\end{array}$} & Yes & $40(18)$ \\
\hline & No & $42(19)$ \\
\hline & Don't know & $18(8)$ \\
\hline \multirow{4}{*}{ Setting where HG patients usually seen } & Inpatient & $78(35)$ \\
\hline & Outpatient & $40(18)$ \\
\hline & Day case setting & $13(6)$ \\
\hline & Other & $4(2)$ \\
\hline \multirow{3}{*}{$\begin{array}{l}\text { Access to day unit rehydration service for } \\
\text { HG patients in place of work }\end{array}$} & Yes & $18(8)$ \\
\hline & No & $44(20)$ \\
\hline & Not sure & $38(17)$ \\
\hline
\end{tabular}

${ }^{1}$ Other main roles included diabetes, dietetic manager, critical care, inherited metabolic disease. NHS: National Health Service. HG: Hyperemesis Gravidarum.

When asked to rate their competence in the dietetic management of HG on a scale of 1 (not at all competent) to 10 (very competent), the majority of respondents $(60 \%, n=27)$ rated their competence as $\geq 6$. Respondents received a median of 3 (IQR 5.3) referrals per year, however these data were very skewed, with a wide range of 1-100. Six (13\%) respondents received $\geq 25$ referrals per year. There was a positive correlation between perceived competence and the number of referrals received per year (Spearmann's rho $0.307, p<0.05)$.

\subsection{Referral Pathway and Criteria}

Midwives were the most likely source of referrals $(64 \%, n=29)$, followed by obstetricians $(42 \%, \mathrm{n}=19)$ and nurses $(40 \%, \mathrm{n}=18)$. The criteria used to refer a patient with HG to a dietitian are shown in Figure 1. Participants were asked to tick all criteria that applied. There were 70 responses, of which the most frequently used referral criteria was the Malnutrition Universal Screening Tool (MUST) $(26 \%, n=18)$, see Figure 1 for details. The 'other' category $(13 \%(n=9)$ responses) included 'patients not able to tolerate oral food', 'non-specific clinical judgement by ward staff' and 'placement of nasogastric tube'. For those who responded that 'percentage weight loss' was used; 5 or $10 \%$ was the stated threshold.

Participants were able to select as many answers as applied in their work setting, therefore the total number of responses exceeds the number of participants. 


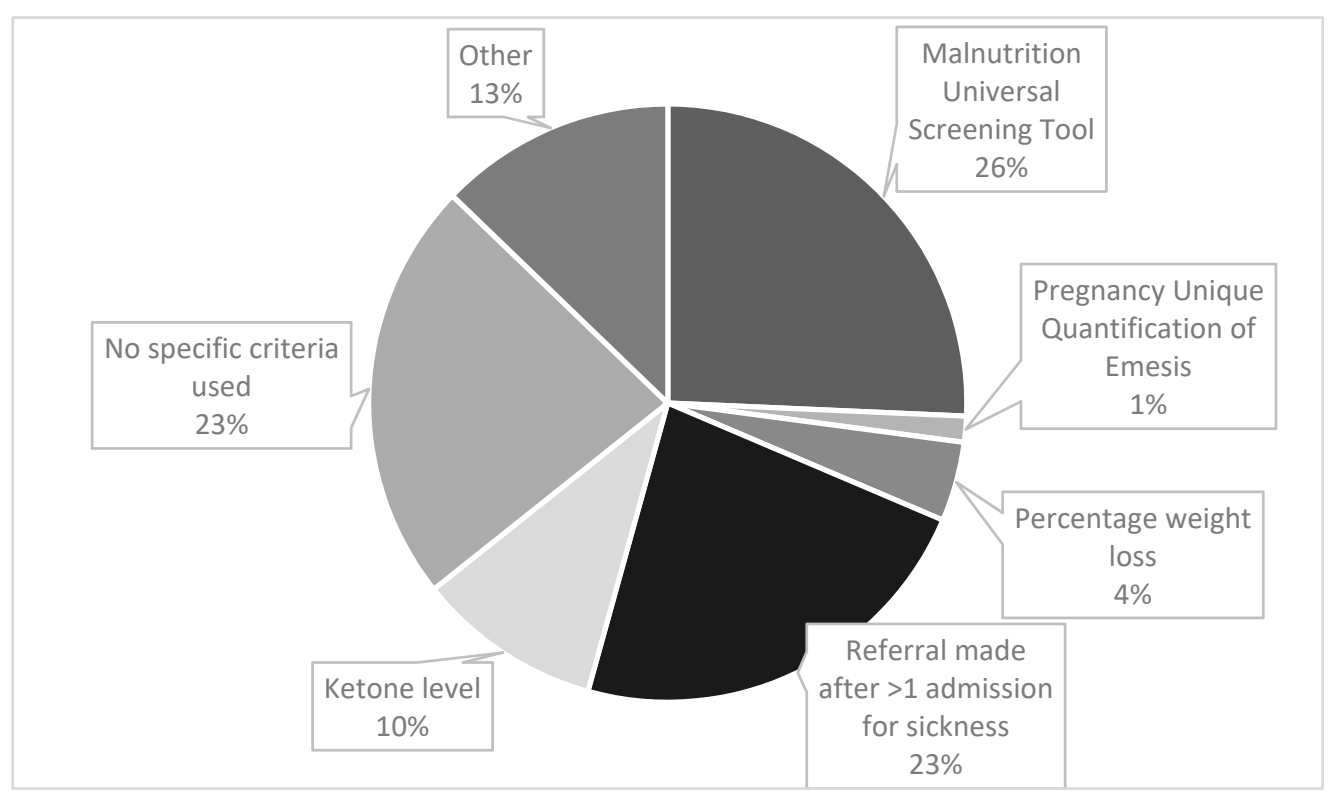

Figure 1. Clinical criteria used to refer a patient with HG for dietetic input.

\subsection{Clinical Management}

An overwhelming majority of respondents $(87 \%, \mathrm{n}=39)$ reported that no specific clinical guidelines were used in the dietetic management of HG. Only $6(13 \%)$ respondents used either a local or national guideline, most commonly the Royal College of Obstetricians \& Gynaecology (RCOG) [7] guidance. Refeeding syndrome guidelines were followed 'most of the time' $(66.7 \%, \mathrm{n}=30)$ or 'some of the time' $(12 \%, \mathrm{n}=6)$. A fifth of respondents $(20 \%, \mathrm{n}=9)$ selected that refeeding syndrome was 'not usually clinically relevant' in their caseload of those with HG.

\subsection{Use of Oral Supplements, Enteral and Parenteral Nutrition Support}

Figure 2 shows how frequently different types of nutrition support are typically used. Oral nutrition supplements (ONS) were most commonly used, with $31 \%(\mathrm{n}=14)$ of respondents stating they were used 'most of the time' and $42 \%(n=19)$ selecting 'sometimes'. In contrast, 38\% $(\mathrm{n}=17)$ and $62 \%(\mathrm{n}=28)$ reported that enteral and parenteral nutrition respectively were never used. Where EF was used, the nasogastric route $(63 \%$, $\mathrm{n}=17)$ was more common than nasojejunal feeding $(37 \%, \mathrm{n}=10)$.

The most commonly selected contraindications to parenteral nutrition (PN) from a predefined list of responses were: 'unlikely to need PN for a sufficient time for risks to outweigh the benefits' $(50 \%, \mathrm{n}=20)$ and 'lack of training in maternity unit' $(45 \%$, $\mathrm{n}=18)$. 'Risk of infection' $(20 \%, \mathrm{n}=8)$ and 'lack of funding/service' $(15 \%, \mathrm{n}=6)$ were also relevant factors.

When respondents were asked to select from a list of what they would find most helpful in supporting those with HG, most $(96 \%, n=43)$ reported they would find specific HG resources useful, with many also selecting 'more training for dietitians' $(78 \%, \mathrm{n}=35)$, including webinars $(69 \%, \mathrm{n}=31)$ and 'more training for other health care professionals' (HCPs) $(62 \%, \mathrm{n}=28)$.

\subsection{Improvement of Care}

When asked what would help optimise the referral rate and dietetic management of pregnancies with HG, 26 individuals gave free text responses. Following categorisation, three key themes emerged, namely:

- A need to increase awareness and training for healthcare professionals;

- Improved guidance for dietetic referral and management of HG;

- Improved capacity/priority for dietitians to cope with the issue. 
Illustrative quotes for these themes (and sub-themes) are shown in Table 2.

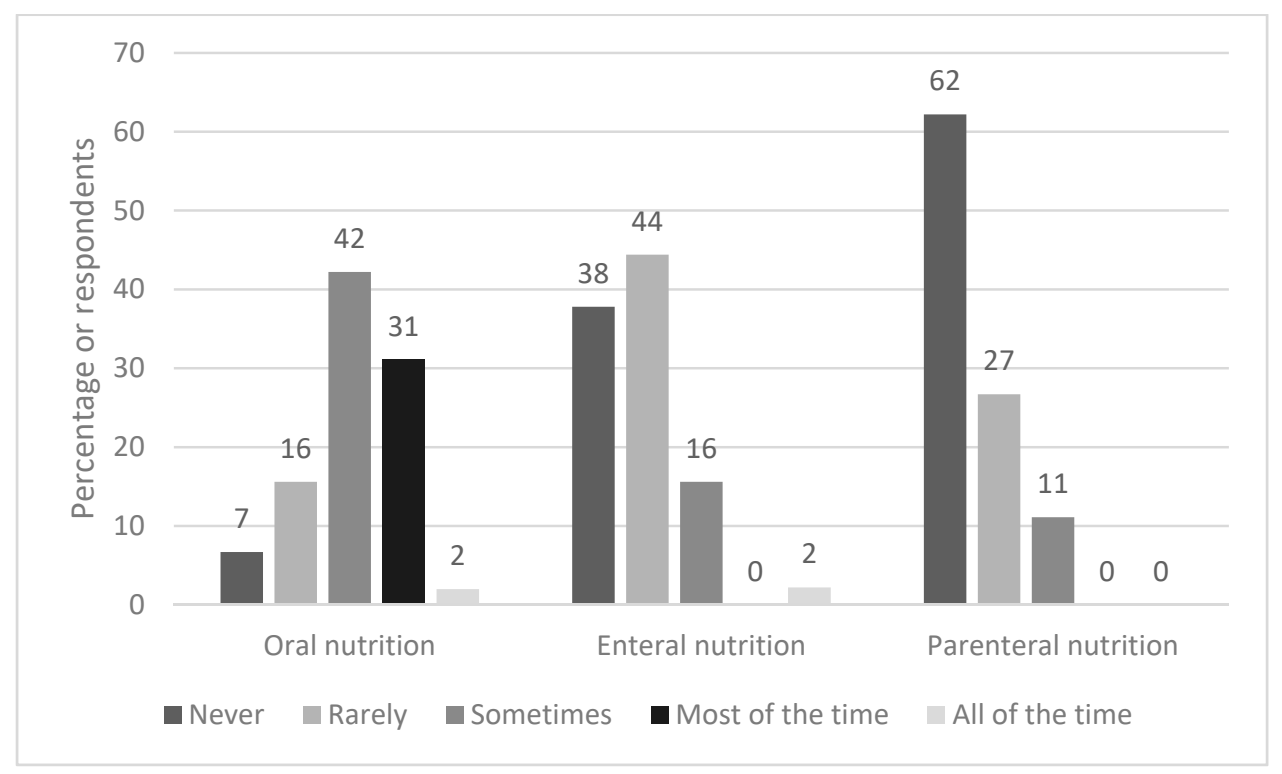

Figure 2. Frequency and type of nutrition support used.

Table 2. Themes from responses to question: 'What would help optimise the referral rate and dietetic management of pregnancies with HG?'

Theme

Need to increase awareness amongst HCPs

1. A need to increase awareness \& training for HCPs

Sub-Theme
Example Quotes

- 'I saw a patient this week and still this idea persists, where the referral stated "it might be psychological" - this woman had lost $>6 \mathrm{~kg}$ in 7-8 weeks'.

- 'Acknowledgement that this is very real and debilitating'.

- 'Raising awareness amongst ward staff'.

- 'More awareness of how serious this condition is'.

- 'Insight into refeeding risk'.

- 'Prompt siting of NJT/PN consideration if vomiting uncontrolled or weight loss is severe'.

- 'Training of multidisciplinary teams (MDT) seeing patients'.

- 'Teaching of doctors and student dietitians'.

- 'Training for staff that these patients are nutritionally at risk'.

Improved training of $\mathrm{HCPs}$

- 'Understanding the value of nutritional supplements'.

- 'Building good working relationships with midwives on antenatal wards'. 
Table 2. Cont.

\begin{tabular}{|c|c|c|}
\hline Theme & Sub-Theme & Example Quotes \\
\hline \multirow{2}{*}{$\begin{array}{l}\text { 2. Improved guidance for dietetic } \\
\text { referral and management of HG }\end{array}$} & $\begin{array}{l}\text { Improved guidance for referral } \\
\text { for dietetic input }\end{array}$ & $\begin{array}{l}\text { - 'MUST ... not always done but is our acceptance } \\
\text { criteria'. } \\
\text { - 'Biochemistry results'. } \\
\text { - 'Screened for \% weight loss and length of time } \\
\text { - } \quad \text { with little or no nutrition'. } \\
\text { 'Tools available to screen patients and agreed } \\
\text { - } \quad \text { referral criteria'. } \\
\text { 'Referral to dietitians on admission ... instead of } \\
\text { waiting for weight loss'. }\end{array}$ \\
\hline & $\begin{array}{l}\text { Improved guidance for dietetic } \\
\text { management }\end{array}$ & $\begin{array}{l}\text { - } \quad \text { 'Specific evidence based guidelines that we could } \\
\text { - } \quad \text { 'Treate with maternity services'. } \\
\text { rehydration and anti-emetics'. } \\
\text { - } \quad \text { 'More specialised service to refer women to and } \\
\text { - } \quad \text { 'Indated literature'. } \\
\text { - } \quad \text { Informatiod training of dietetic management of } \mathrm{HG}^{\prime} \text { '. } \\
\text { follow e.g., vitamins to consider ... or a list of } \\
\text { services ... to refer the patient on'. }\end{array}$ \\
\hline $\begin{array}{l}\text { 3. Improved capacity/priority for } \\
\text { dietitians to cope with the issue }\end{array}$ & & $\begin{array}{l}\text { - 'Funding for dietetics, research into impact and } \\
\text { benefits of dietetics'. } \\
\text { - 'We don't have the capacity to advertise dietetics to } \\
\text { this group of service users'. } \\
\text { - 'Increased profile of dietetics among other HCPs'. } \\
\text { - 'If people thought dietitians could do more'. } \\
\text { - } \quad \text { 'Specific funding for maternity care'. }\end{array}$ \\
\hline
\end{tabular}

HCP: Health Care Professionals $\rightarrow$ NJT: Nasojejunal Tube $\rightarrow$ PN: Parenteral Nutrition $\rightarrow$ MUST: Malnutrition Universal Screening Tool HG: Hyperemesis Gravidarum.

\section{Discussion}

This study aimed to explore dietetic involvement in the management of HG; to our knowledge, the first to research this topic. The results from 45 respondents demonstrate a lack of specific nutritional guidelines and patient resources for this patient group, with inconsistency in nutritional screening and referral practices. The numbers of patients seen per year was very low, although this varied considerably, with only a small minority of respondents having a specialist maternal health role. Although EN and PN were reported to be used infrequently, ONS were used more regularly. The key themes for improvement of dietetic referral and management show that participants were keenly aware of the nutritional risk to women with HG and the need for nutritional care to improve.

The most commonly used referral criteria was via MUST $(40 \%, n=18)$, a tool based on a composite score derived from three independent criteria: current body mass index (BMI), (unintentional) weight loss and acute disease effect score. The acute disease effect component is defined as 'acutely ill and where there has been or is likely to be no nutritional intake for $>5$ days'. Meeting this criteria alone, equates to a 'high risk for malnutrition', with the algorithm recommending referral to a dietitian [24]. Therefore even without incurring any score for the other two criteria, a person experiencing severe HG symptoms with minimal oral intake, would be classified as high risk. MUST is valid, reliable and authors recommend it can be applied to pregnancy with cautious interpretation [24]. Authors recommend that recalled weight could be used to estimate pre-pregnancy BMI category and that weight gain of $<1 \mathrm{~kg}(<0.5 \mathrm{~kg}$ in those with obesity) during the 2nd and 3rd trimester generally requires further evaluation [24]. From this survey, it is unclear if MUST was adapted for pregnancy. Other authors suggest a pragmatic threshold of $8-10 \%$ prepregnancy weight loss warrants further nutritional intervention [9], although in our study weight loss was not a common referral criteria $(7 \%, n=3)$. 
Regarding other referral criteria, the second most common was 'being referred after one admission with vomiting' $(36 \%, \mathrm{n}=16)$. This may mean that those who are admitted once are never referred to a dietitian, and no objective nutritional screening is undertaken. An analysis of hospital admission data in England between 1998 and 2012 [4], found the readmission rate for HG was $28 \%$, with $11 \%$ having $\geq 3$ admissions. This implies that $72 \%$ would not meet the threshold for dietetic referral, even with significant weight loss and/or poor oral intake. However hospital admissions and symptom severity are not always correlated and admissions may be partly related to demographic factors, with some preferring to stay at home [4]. Qualitative research has also found that many of those with HG do not access treatment, which can be attributed to a number of factors, including stigma [25]. Conversely, an analysis of $>400,000$ pregnancies in England concluded that the low-level prescription of anti-emetics in primary care, may mean that women who could be well managed in the community, present for hospital admission [4]. Therefore hospital readmission is not likely to be a valid indicator of nutritional risk.

Some $36 \%(n=16)$ of responses indicated that 'no specific referral criteria was used' thus underlining that better and more consistent nutritional screening is needed. Nutritional screening is a rapid, simple and general procedure used by nursing, medical or other healthcare staff, often at first contact with the patient, to detect those with significant risk of nutritional problems, so that clear guidelines for action can be implemented [24]. Improved training of medical and nursing staff in nutritional screening was recommended by our respondents. However, the physiological changes that occur during pregnancy mean standard malnutrition assessment tools and biochemical reference ranges used in the adult non-pregnant population are not always appropriate, with specific definitions and criteria for malnutrition during pregnancy or 'gestational malnutrition' lacking from current international guidelines [26,27]. As such, a recent systematic review concluded that more research is needed to examine the validity and reliability of screening/assessment tools in identifying malnutrition in pregnancy [28].

A more detailed integrated dietetic pathway with thresholds of how to escalate nutritional care is warranted. This was a major theme when respondents were asked what would improve dietetic management. Anecdotally, first line dietary advice has included avoiding fatty/odorous foods/eating on an empty stomach, eating dry crackers and/or eating a high-protein snack before bed [29,30]; which may provide some symptomatic relief in those with mild/moderate symptoms [31,32]. However, there has been no evidencebased research on the effectiveness of these approaches or any other dietary or lifestyle interventions in HG [19]. For the severe symptoms of HG, lifestyle and dietary changes alone are insufficient [8]. This is particularly relevant to our respondents, the vast majority of whom work in hospitals. Of note there has been little research conducted on the use of ONS in HG, which may be a useful nutritional treatment option, given that $73 \%(n=33)$ of our respondents used ONS either 'sometimes' or 'most of the time'.

The results showed that nasogastric feeding was more common than the nasojejunal route. NJT placement is less straightforward than NGT as it requires placement of the distal end of the feeding tube beyond the gastric pyloric sphincter, however it may be less likely to be dislodged by vomiting. Overall the evidence base for the use of tube feeding in HG is inconsistent. A retrospective case series of 558 hospitalised women in Norway, found that compared with other fluid/nutrition regimens, EN was a feasible treatment option, associated with adequate maternal weight gain and favourable pregnancy outcomes [21] In contrast, a randomised controlled trial based in the Netherlands, that compared EN for 7 days to standard care, did not find any improvement in birth weight or secondary outcomes [18]. Of note, there was a poor protocol completion in the group allocated to EN, with $\sim 7 \%$ refusing tube placement, and an unanticipated $34 \%$ discontinuing EN because of adverse effects. Conversely, a small qualitative study of 13 women [25], found that those without EN $(n=5)$, expressed a desire for EN, in order to prevent severe weight loss, dehydration and weakness, to provide sufficient nutrition for the baby and to prevent further admissions. In the UK, EN is viewed as an effective, but extreme method, often 
used as a last resort. However some of the responses to the survey suggested that NG/NJT should be sited proactively rather than waiting for weight loss to worsen. This is a common strategy in other clinical scenarios in those at risk of malnutrition and where there is insufficient nutrition taken via the oral route [27]. The finding that only $11 \%(n=5)$ used total PN 'sometimes', is reflective of guidance that it should only be used in refractory cases when 'all other medical therapies have failed'.

This study has a number of limitations. Due to the small sample size, inferential statistics were not possible. Attempts were made to maximise recruitment, by cascading the questionnaire, however equally, the small sample size may be reflective of the low numbers of referrals made to dietitians for pregnancies affected by HG, rather than a low response rate. Previous UK research reported that dietetic resources for specialist maternity services were inadequate despite dietitians recognising the importance of nutritional counselling during pregnancy [33]. Responses were based on self-report, rather than clinical records. The survey used lists of predefined responses, however the responses were developed and piloted with dietitians. As the study was UK-based, it may not be externally generalisable. Strengths of the study are the variety of participants working in different roles, settings and the four countries of the UK.

\section{Conclusions}

$\mathrm{HG}$ is an extremely debilitating condition that often requires hospital admission and can have severe nutritional consequences for both maternal and fetal health. Our results indicate there is currently an inconsistent approach in referring those with HG for dietetic input, combined with a lack of nutritional-specific guidelines and pathways. Improved training and education of all HCPs and the development of evidence-based nutritional guidelines, with enhanced funding for dietitians were suggested ways to improve care to this population group.

Supplementary Materials: The following are available online at https:/ /www.mdpi.com/article/10 $.3390 /$ nu13061964/s1, file S1: questionnaire.

Author Contributions: Study conceptualisation K.M.; methodology, K.M., H.A.B., C.R.D., J.A., analysis: K.M., J.A. writing—original draft preparation, K.M.; writing—review and editing, K.M., H.A.B., C.R.D., J.A. All authors have read and agreed to the published version of the manuscript.

Funding: This research received no external funding.

Institutional Review Board Statement: Ethical approval was granted by the University of Plymouth, Faculty of Health, Research Ethics and Integrity Committee (reference 19/20-1322).

Informed Consent Statement: Informed consent was obtained from all subjects involved in the study.

Data Availability Statement: The data presented in this study are available on request from the corresponding author.

Acknowledgments: We thank Niamh Keane, Catherine Foley, Paula McGurk and the Pregnancy Sickness Support Charity for reviewing and piloting the questionnaire. Thanks also to the British Dietetic Association, its specialist groups and the respondents.

Conflicts of Interest: The authors declare no conflict of interest.

\section{References}

1. Einarson, T.R.; Piwko, C.; Koren, G. Quantifying the global rates of nausea and vomiting of pregnancy: A meta analysis. J. Popul. Ther. Clin. Pharmacol. 2013, 20, e171-e183. [PubMed]

2. Fiaschi, L.; Nelson-Piercy, C.; Tata, L.J. Hospital admission for hyperemesis gravidarum: A nationwide study of occurrence, reoccurrence and risk factors among 8.2 million pregnancies. Hum. Reprod. 2016, 31, 1675-1684. [CrossRef] [PubMed]

3. Vikanes, A.; Grjibovski, A.M.; Vangen, S.; Magnus, P. Variations in prevalence of hyperemesis gravidarum by country of birth: A study of 900,074 pregnancies in Norway, 1967-2005. Scand. J. Public Health 2008, 36, 135-142. [CrossRef]

4. Fiaschi, L.; Nelson-Piercy, C.; Deb, S.; King, R.; Tata, L.J. Clinical management of nausea and vomiting in pregnancy and hyperemesis gravidarum across primary and secondary care: A population-based study. Br. J. Obstet. Gynaecol. 2019, 126, 1201-1211. [CrossRef] [PubMed] 
5. Nurmi, M.; Rautava, P.; Gissler, M.; Vahlberg, T.; Polo-Kantola, P. Incidence and risk factors of hyperemesis gravidarum: A national register-based study in Finland, 2005-2017. Acta Obstet. Gynecol. Scand. 2020, 99, 1003-1013. [CrossRef] [PubMed]

6. Einarson, T.R.; Piwko, C.; Koren, G. Prevalence of nausea and vomiting of pregnancy in the USA: A meta analysis. J. Popul. Ther. Clin. Pharmacol. 2013, 20, e163-e170. [PubMed]

7. Royal College of Obstetricians and Gynaecologists. The Management of Nausea and Vomiting of Pregnancy and Hyperemesis Gravidarum; Green-top Guideline No. 69; RCOG: London, UK, June 2016.

8. Fejzo, M.S.; Trovik, J.; Grooten, I.J.; Sridharan, K.; Roseboom, T.J.; Vikanes, Å.; Painter, R.C.; Mullin, P.M. Nausea and vomiting of pregnancy and hyperemesis gravidarum. Nat. Rev. Dis. Primers 2019, 5, 62. [CrossRef]

9. Macgibbon, K.W. Hyperemesis Gravidarum: Strategies to Improve Outcomes. J. Infus. Nurs. 2020, 43, 78-96. [CrossRef]

10. Mullin, P.M.; Ching, C.; Schoenberg, F.; MacGibbon, K.; Romero, R.; Goodwin, T.M.; Fejzo, M.S. Risk factors, treatments, and outcomes associated with prolonged hyperemesis gravidarum. J. Matern. Fetal Neonatal Med. 2012, 25, 632-636. [CrossRef]

11. Fejzo, M.S.; Poursharif, B.; Korst, L.M.; Munch, S.; MacGibbon, K.W.; Romero, R.; Goodwin, T.M. Symptoms and pregnancy outcomes associated with extreme weight loss among women with hyperemesis gravidarum. J. Women's Health 2009, 18, 1981-1987. [CrossRef]

12. Ayyavoo, A.; Derraik, J.G.; Hofman, P.L.; Biggs, J.; Bloomfield, F.H.; Cormack, B.E.; Stone, P.; Cutfield, W.S. Severe hyperemesis gravidarum is associated with reduced insulin sensitivity in the offspring in childhood. J. Clin. Endocrinol. Metab. 2013, 98, 3263-3268. [CrossRef] [PubMed]

13. Getahun, D.; Fassett, M.J.; Jacobsen, S.J.; Xiang, A.H.; Takhar, H.S.; Wing, D.A.; Peltier, M.R. Autism Spectrum Disorders in Children Exposed in Utero to Hyperemesis Gravidarum. Am. J. Perinatol. 2019. [CrossRef]

14. Fejzo, M.; MacGibbon, K.; Mullin, P.M. Why are Women Still Dying from Nausea and Vomiting of Pregnancy? Gynecol. Obstet. Case Rep. 2016, 2, 1-4. [CrossRef]

15. Fejzo, M.S.; Sazonova, O.V.; Sathirapongsasuti, J.F.; Hallgrimsdottir, I.B.; Vacic, V.; MacGibbon, K.W.; Schoenberg, F.P.; Mancuso, N.; Slamon, D.J.; Mullin, P.M. Placenta and appetite genes GDF15 and IGFBP7 are associated with hyperemesis gravidarum. Nat. Commun. 2018, 9, 1178. [CrossRef] [PubMed]

16. O’Donnell, A.; McParlin, C.; Robson, S.C.; Beyer, F.; Moloney, E.; Bryant, A.; Bradley, J.; Muirhead, C.; Nelson-Piercy, C.; Newbury-Birch, D.; et al. Treatments for hyperemesis gravidarum and nausea and vomiting in pregnancy: A systematic review and economic assessment. Health Technol. Assess 2016, 20, 1-268. [CrossRef]

17. Maslin, K.; Shaw, V.; Dean, C.; Brown, A.; Shawe, J. What is known about the nutritional intake of women with Hyperemesis Gravidarum? A scoping review. Eur. J. Obstet. Reprod. Biol. 2020, 257, 76-83. [CrossRef]

18. Grooten, I.J.; Mol, B.W.; van der Post, J.A.M.; Ris-Stalpers, C.; Kok, M.; Bais, J.M.J.; Bax, C.J.; Duvekot, J.J.; Bremer, H.A.; Porath, M.M.; et al. Early nasogastric tube feeding in optimising treatment for hyperemesis gravidarum: The MOTHER randomised controlled trial (Maternal and Offspring outcomes after Treatment of HyperEmesis by Refeeding). BMC Pregnancy Childbirth 2016, 16, 1-6. [CrossRef]

19. Boelig, R.C.; Barton, S.J.; Saccone, G.; Kelly, A.J.; Edwards, S.J.; Berghella, V. Interventions for treating hyperemesis gravidarum. Cochrane Database Syst. Rev. 2016, CD010607. [CrossRef]

20. Dean, C.R.; Bierma, H.; Clarke, R.; Cleary, B.; Ellis, P.; Gadsby, R.; Gauw, N.; Lodge, K.; MacGibbon, K.; McBride, M.; et al. A patient-clinician James Lind Alliance partnership to identify research priorities for hyperemesis gravidarum. BMJ Open 2021, 11, e041254. [CrossRef]

21. Stokke, G.; Gjelsvik, B.L.; Flaatten, K.T.; Birkeland, E.; Flaatten, H.; Trovik, J. Hyperemesis gravidarum, nutritional treatment by nasogastric tube feeding: A 10-year retrospective cohort study. Acta Obstet. Gynecol. Scand. 2015, 94, 359-367. [CrossRef]

22. IBM. IBM SPSS Statistics for Windows, Version 24.0; IBM Corp: Armonk, NY, USA, 2016.

23. Braun, V.; Clarke, V. Using thematic analysis in psychology. Qual. Res. Psychol. 2006, 3, 77-101. [CrossRef]

24. Elia, M. The 'MUST' Report. Nutritional Screening of Adults: A Multidisciplinary Responsibility. Development and Use of the 'Malnutrition Universal Screening Tool' ('MUST') for Adults, Malnutrition Advisory Group (MAG), Standing Committee of BAPEN., Redditch, Worcs. 2003. Available online: https://www.bapen.org.uk/pdfs/must/must-report.pdf (accessed on 15 March 2021).

25. Havnen, G.C.; Truong, M.B.; Do, M.H.; Heitmann, K.; Holst, L.; Nordeng, H. Women's perspectives on the management and consequences of hyperemesis gravidarum-A descriptive interview study. Scand. J. Prim. Health Care 2019, 37, 30-40. [CrossRef] [PubMed]

26. Cederholm, T.; Barazzoni, R.; Austin, P.; Ballmer, P.; Biolo, G.; Bischoff, S.C.; Compher, C.; Correia, I.; Higashiguchi, T.; Holst, M.; et al. ESPEN guidelines on definitions and terminology of clinical nutrition. Clin. Nutr. 2017, 36, 49-64. [CrossRef] [PubMed]

27. National Institute for Health and Care Excellence. Nutrition Support for Adults: Oral Nutrition Support, Enteral Tube Feeding and Parenteral Nutrition; Clinical Guidelines [CG32]; National Institute for Health and Care Excellence: London, UK, 2006; Updated 2017.

28. Academy of Nutrition and Dietetics Evidence Analysis Library. Malnutrition in Pregnancy Systematic Review. 2018. Available online: https: / / www.andeal.org/topic.cfm?menu=5529 (accessed on 15 March 2021).

29. Ebrahimi, N.; Maltepe, C.; Einarson, A. Optimal management of nausea and vomiting of pregnancy. Int. J. Women's Health 2010, 2, 241-248. [CrossRef] 
30. King, T.L.; Murphy, P.A. Evidence-based approaches to managing nausea and vomiting in early pregnancy. J. Midwifery Women's Health 2009, 54, 430-444. [CrossRef]

31. Chandra, K.; Magee, L.; Einarson, A.; Koren, G. Nausea and vomiting in pregnancy: Results of a survey that identified interventions used by women to alleviate their symptoms. J. Psychosom. Obstet. Gynaecol. 2003, 24, 71-75. [CrossRef]

32. Goodwin, T.M.; Poursharif, B.; Korst, L.M.; MacGibbon, K.W.; Romero, R.; Fejzo, M.S. Secular trends in the treatment of hyperemesis gravidarum. Am. J. Perinatol. 2008, 25, 141-147. [CrossRef] [PubMed]

33. McSherry, C.; Belton, E.A. A survey of the opinions, attitudes, and current involvement of UK dietitians in antenatal and maternity care services. J. Hum. Nutr. Diet. 2009, 22, 256-275. [CrossRef] 